Supplement of The Cryosphere, 16, 379-395, 2022 https://doi.org/10.5194/tc-16-379-2022-supplement (c) Author(s) 2022. CC BY 4.0 License.

(c) (1)

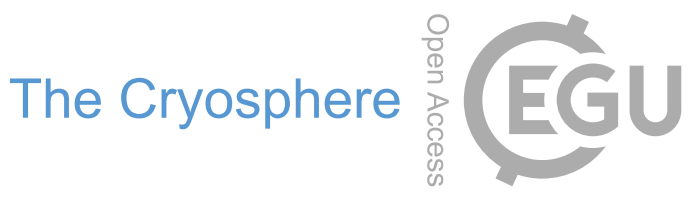

Supplement of

\title{
Radar sounding survey over Devon Ice Cap indicates the potential for a diverse hypersaline subglacial hydrological environment
}

\section{Anja Rutishauser et al.}

Correspondence to: Anja Rutishauser (rutishauser.anja@gmail.com)

The copyright of individual parts of the supplement might differ from the article licence. 


\section{Definition of new lakeshores over T2}

New lake shores are derived from a combination of elevated basal reflectivity and hydraulic flatness in a two-step process: First, preliminary lake shores over bedrock trough T2 are defined on a grid cell by grid cell basis (using the $500 \mathrm{~m}$ hydraulic head mesh), where a grid cell is defined as part of a subglacial water body if the cell has a hydraulic slope $\leq 0.7^{\circ}$, corresponding to the mean slope over the $\mathrm{T} 2$ trough region, and has a mean reflectivity $\mathrm{R}$ anomaly $\geq 8.1 \mathrm{~dB}$, corresponding to one-standard deviation from the mean of all observed reflectivities beneath DIC (Fig. S1). The R $\geq 8.1 \mathrm{~dB}$ criteria here is reduced compared to one used for the identification of subglacial water from individual data points ( $R \geq 12 \mathrm{~dB}$ ) as the reflectivities here are averaged over the grid cells and possibly include lake-margin areas. Neighboring grid cells that are not hydraulically flat, but pass the reflectivity threshold $\mathrm{R} \geq 8.1 \mathrm{~dB}$ are included, allowing the inclusion of areas with shallow water near the lake shores where a hydrostatic equilibrium may not be fully developed. In contrast, stand-alone grid cells where the above thresholds apply are neglected. Finally, the shorelines are manually refined based on visual inspection of basal reflectivities along the radar transects. This allows for a more precise identification of the shorelines compared to the algorithm, which averages reflectivity values over the grid cells (Fig. S1). As such, the grid cells clustered in the eastern part of the trough $(\sim 440 \mathrm{~km}$ Easing) that pass the above defined thresholds for the hydraulic flatness and reflectivity are excluded from our lakeshore definitions due to generally lower along-track reflectivity $(\mathrm{R} \leq 12 \mathrm{~dB})$.

\section{Comparison of laser altimetry and ArcticDEM surface elevation}

To evaluate the ArcticDEM ice surface (100 m composite) as input for the calculation of the subglacial hydraulic head/slope, and to estimate the uncertainty of the ArcticDEM over DIC, we compare the ArcticDEM to laser altimetry measurements (with a rms crossover error of $21 \mathrm{~cm}$ ) conducted during the SRH1 aerogeophysical survey. Our analysis reveals a mean offset of 0.7 $\mathrm{m}$, with a standard deviation of $3.7 \mathrm{~m}$ (Fig. S2). We use the $3.7 \mathrm{~m}$ standard deviation as an uncertainty estimate for the ArcticDEM-derived ice surface elevation, which is above the $0.5 \mathrm{~m}$ estimate reported by the ArcticDEM providers (Porter et al., 2018).

\section{Specularity content threshold justification}

We use a specularity content threshold of 0.4 for declaring a detection of possible subglacial water. Theory suggests that value for an individual detection should be as high as 0.9 (Schroeder et al., 2015). However, we allow for a lower threshold in the context of the filtering process necessary when deriving the specularity content (Fig. S3b) and the noise in the bed power difference between the 1D and 2D focused products (Fig. S3c), to which the specularity content algorithm has a non-linear response (Fig. S4). Noise between the 2D and 1D bed power difference can be caused by several sources, including instability in the semi-automatic bed picking, differences in the horizontal resolution between the two focusing aperture lengths, and clutter. Our results show that even over specular areas, such as the area over the hypothesised subglacial lake in T2, 
considerable small-scale variations (noise) in the 1D and 2D focussed bed power occur (Fig. S3c). The noise is then propagated into the specularity algorithm (Schroeder et al., 2015, Eq. 6), where the relationship between the specularity content and bed power difference becomes hyperbolic where the 2D focused bed power is smaller than the 1D focused bed power (Fig. S4). Using the standard deviation of the 2D-1D focused bed power over the hypothesized lake area as an uncertainty estimate (grey shaded area in Fig. S3c), it becomes clear that the 0.4 specularity threshold is well above the lowest expected specularity value (0.13) within this uncertainty band (Fig. S4).

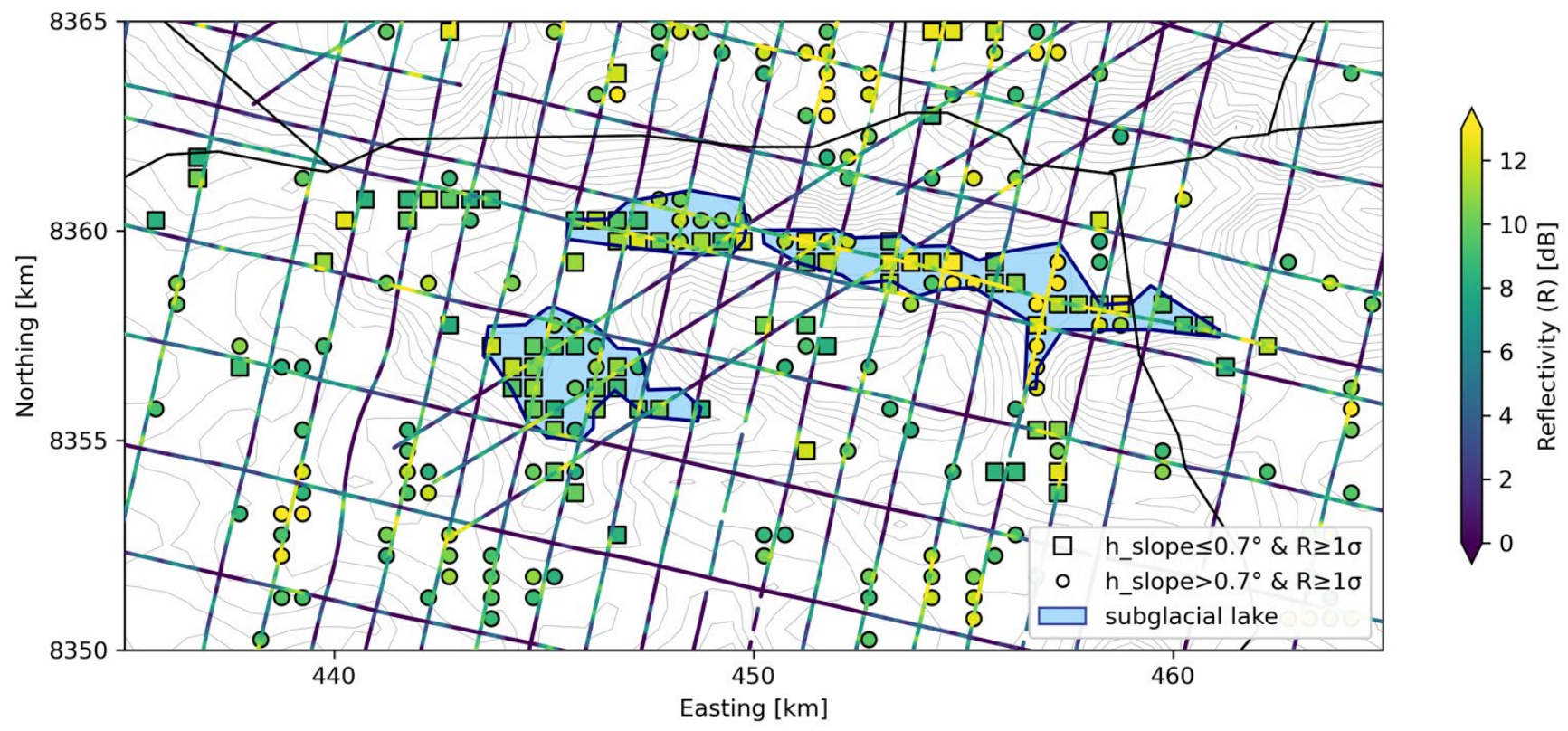

Figure S1. Illustration of criteria used for the definition of the new shorelines of the subglacial lakes in bedrock trough T2. The radar survey lines are color coded with the smoothed along-track basal reflectivity normalized around the mean. The same color code is applied to the squares and circles, which represent the mean reflectivity within a grid cell of the hydraulic head. Squares represent grid cells which pass both the reflectivity and hydraulic flatness criteria for a subglacial lake while circles only pass the reflectivity criteria. These areas are only included when neighboring grid cells pass both criteria (squares), and potentially indicate areas of bridging stresses or shallow water/saturated sediments near the lake shorelines. Thin black lines represent the bedrock topography ( $25 \mathrm{~m}$ interval) whereas thick black lines mark the location of the ice divides. 


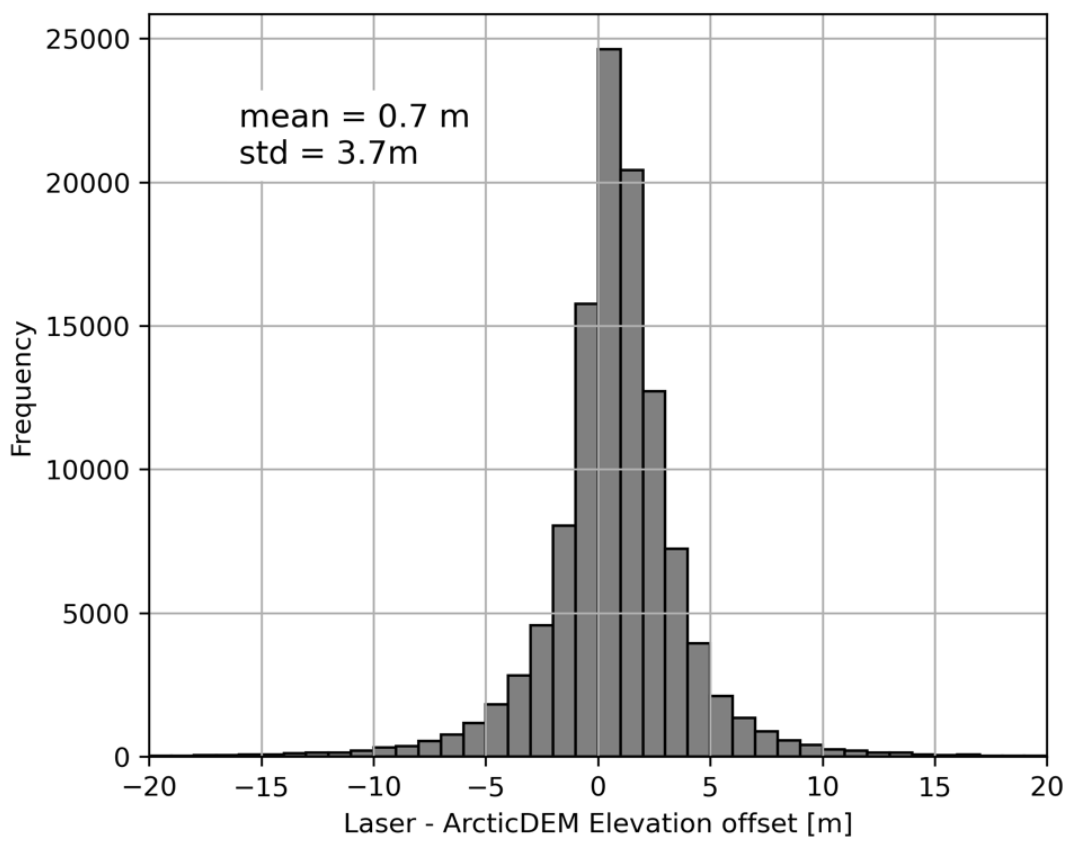

Figure S2. Comparison of ArcticDEM to laser altimetry measurements. The distribution of offsets between airborne laser altimetry ice surface elevation measurements and the ArcticDEM over Devon Ice Cap reveals a mean offset of $0.7 \mathrm{~m}$ with a standard deviation of $3.7 \mathrm{~m}$. 

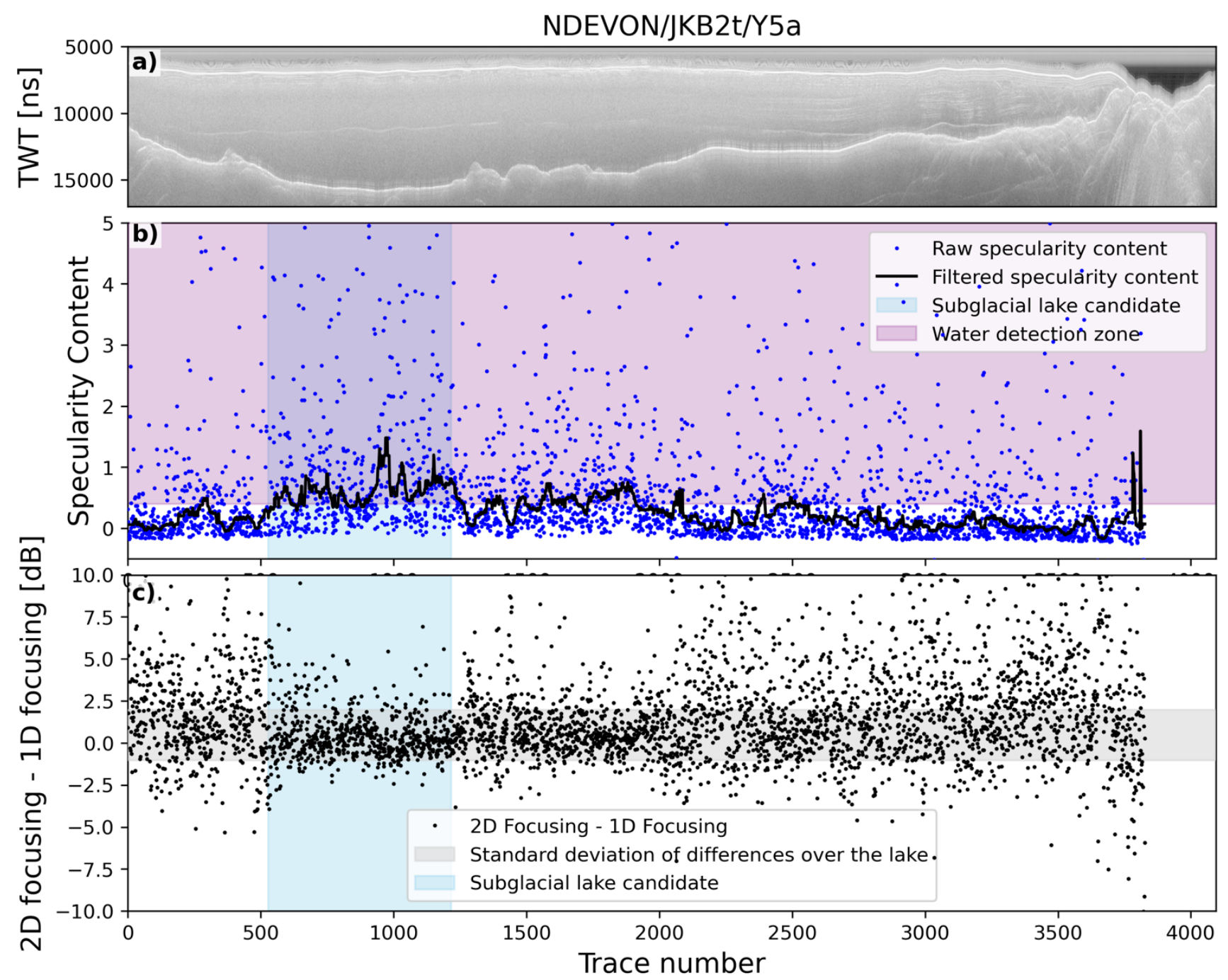

Fig S3. Specularity content along a sample profile (IRSPC2_2018153_NDEVON_JKB2t_Y5a.txt). a) Radargram of a transect flown along the bedrock trough T2 and the hypothesized subglacial lake. b) Raw (blue dots) and filtered (black line) specularity content. The blue shaded rectangle marks the area identified as subglacial lakes (A and B) in this study. The purple shaded box shows where we count the filtered data towards possible water detection (specularity content above 0.4 ). 


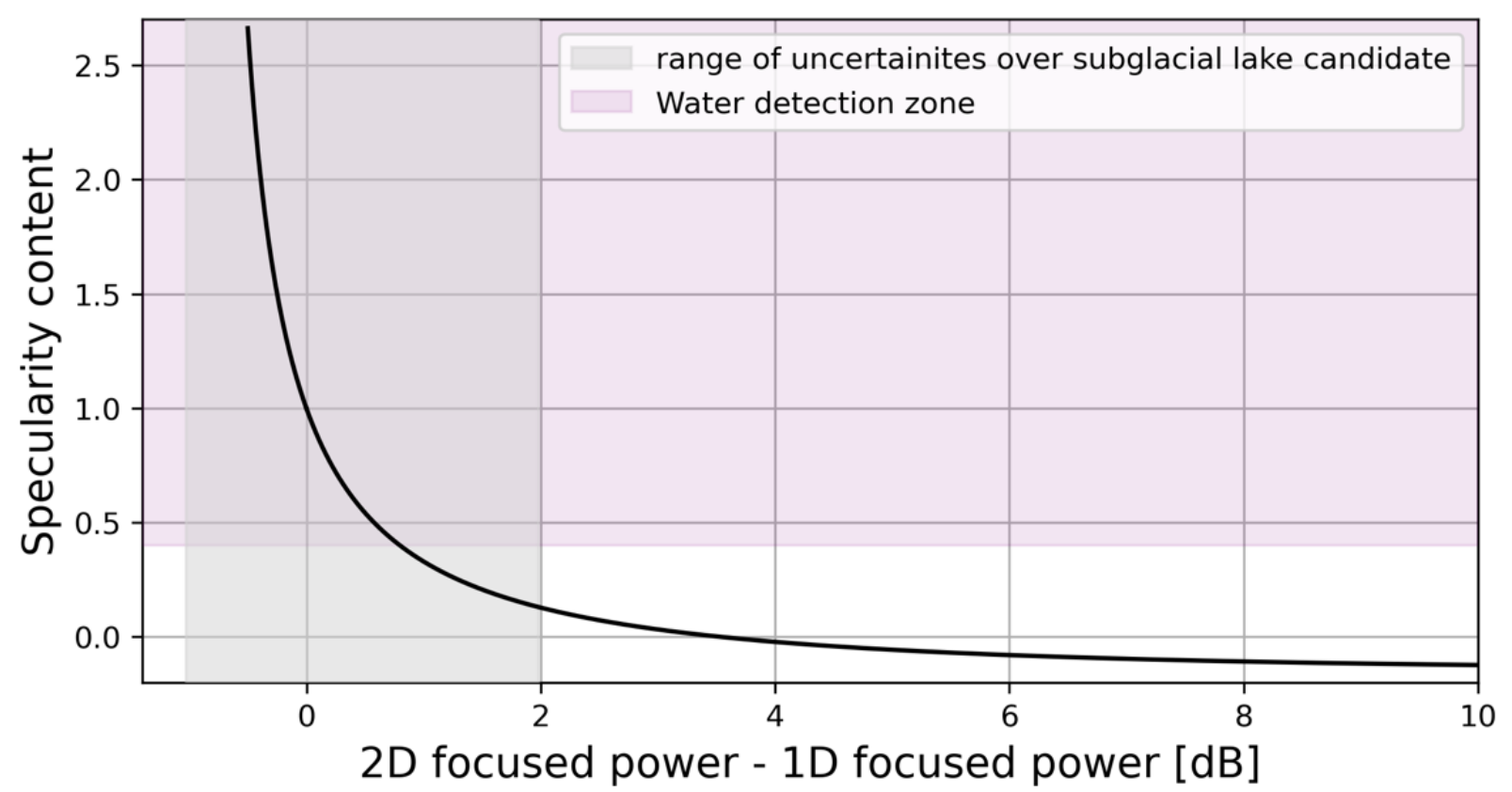

Figure S4. Relationship between the specularity content and the difference in bed power from the 2D and 1D focused products. The specularity content is derived following Eq.6. in Schroeder et al. (2015) using 1D and 2D aperture lengths of $700 \mathrm{~m}$ and $2011 \mathrm{~m}$, respectively, an aircraft height above ice of $500 \mathrm{~m}$, and an ice thickness of $800 \mathrm{~m}$. The grey shaded area shows the uncertainty range in 2D minus $1 \mathrm{D}$ focused bed power derived over the subglacial lake candidate (Fig. S3c). The purple shaded area shows the specularity content values above the 0.4 threshold, potentially indicating areas of subglacial water. 


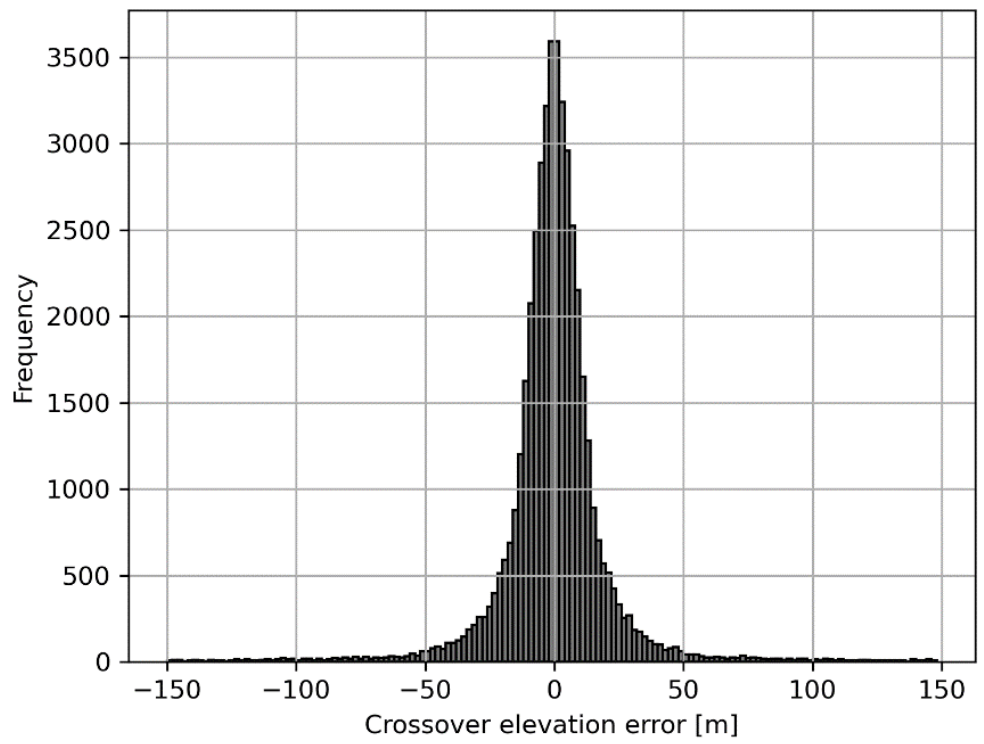

Figure S5. Distribution of bed elevation errors at radar sounding crossover points. A total of 47233 crossover points reveal a mean error of $0.1 \mathrm{~m}$ with a standard deviation of $46 \mathrm{~m}$. 


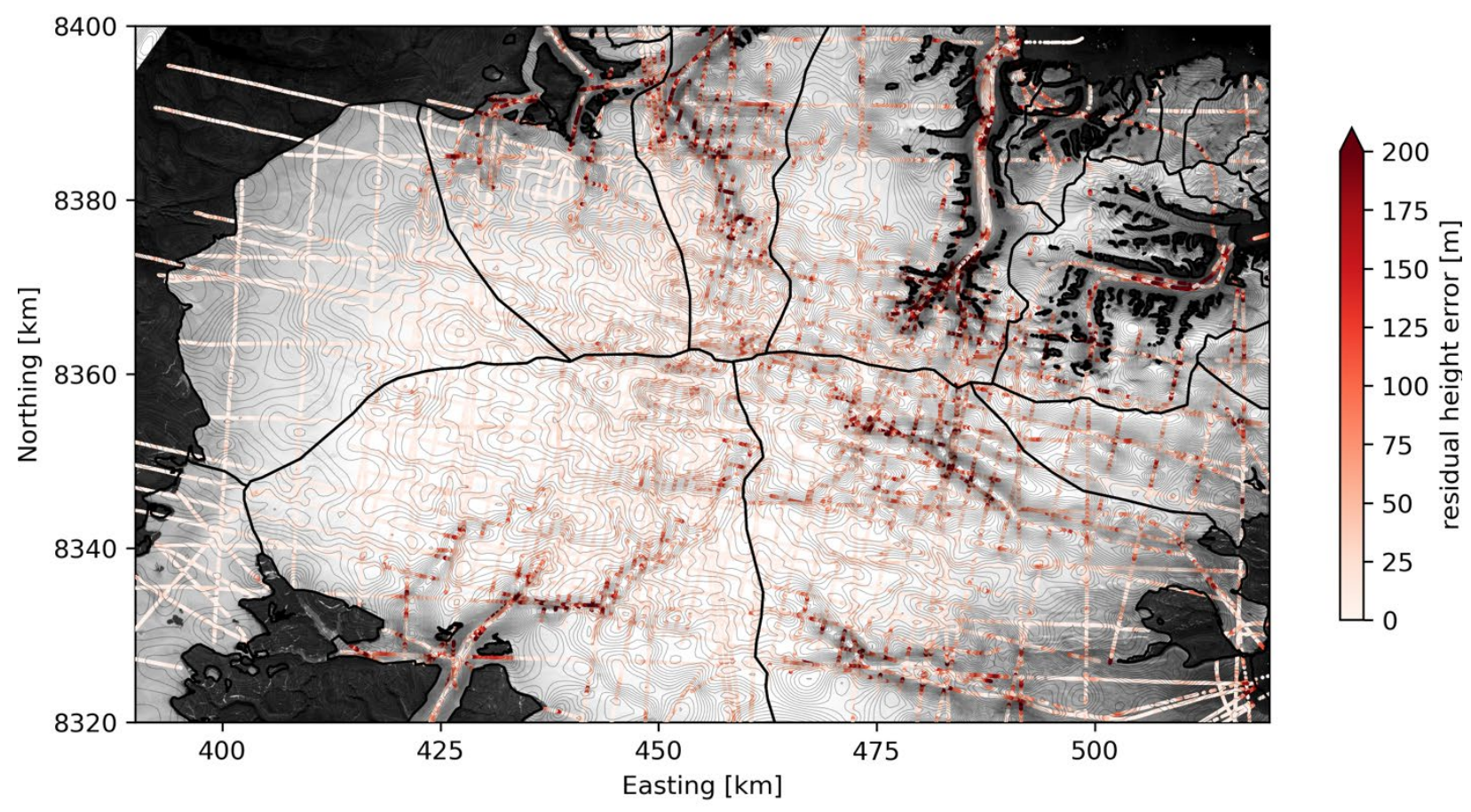

Figure S6. Absolute difference between the bedrock DEM and bed elevation data points along the radar transects. Thin black lines represent the $25 \mathrm{~m}$ bed DEM contour lines. 


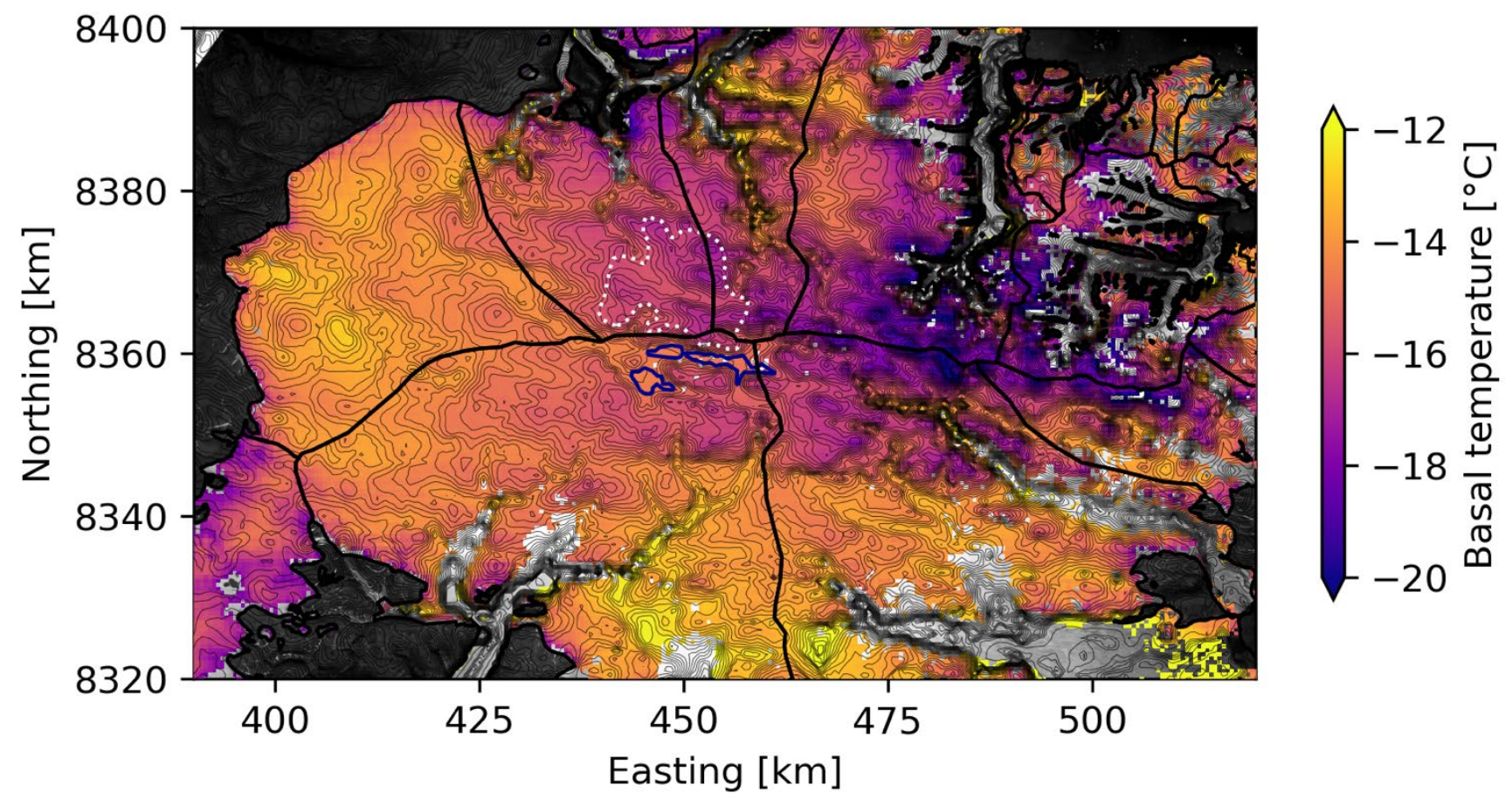

Figure S7. Basal ice temperature. Derived where the ice velocity is below $20 \mathrm{~m} / \mathrm{yr}$, using the same model and parameters as described in (Rutishauser et al., 2018). Outlines of the subglacial lakes A-C (blue) and the brine network (white dotted) are marked. 

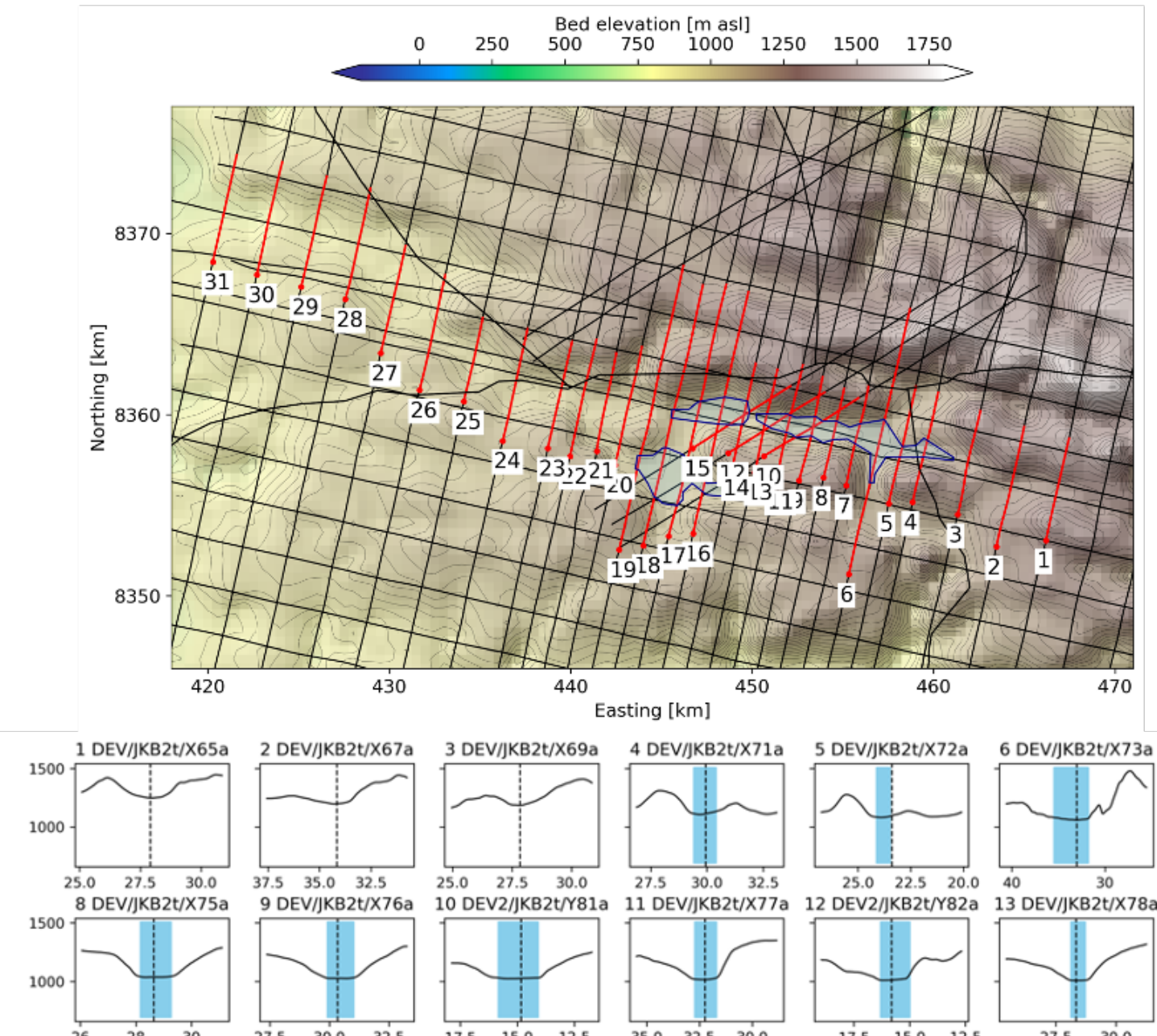

$13 \mathrm{DEV} / \mathrm{JKB} 2 \mathrm{t} / \mathrm{X78a} 14 \mathrm{DEV} / \mathrm{JKB} 2 \mathrm{t} / \mathrm{X79a}$
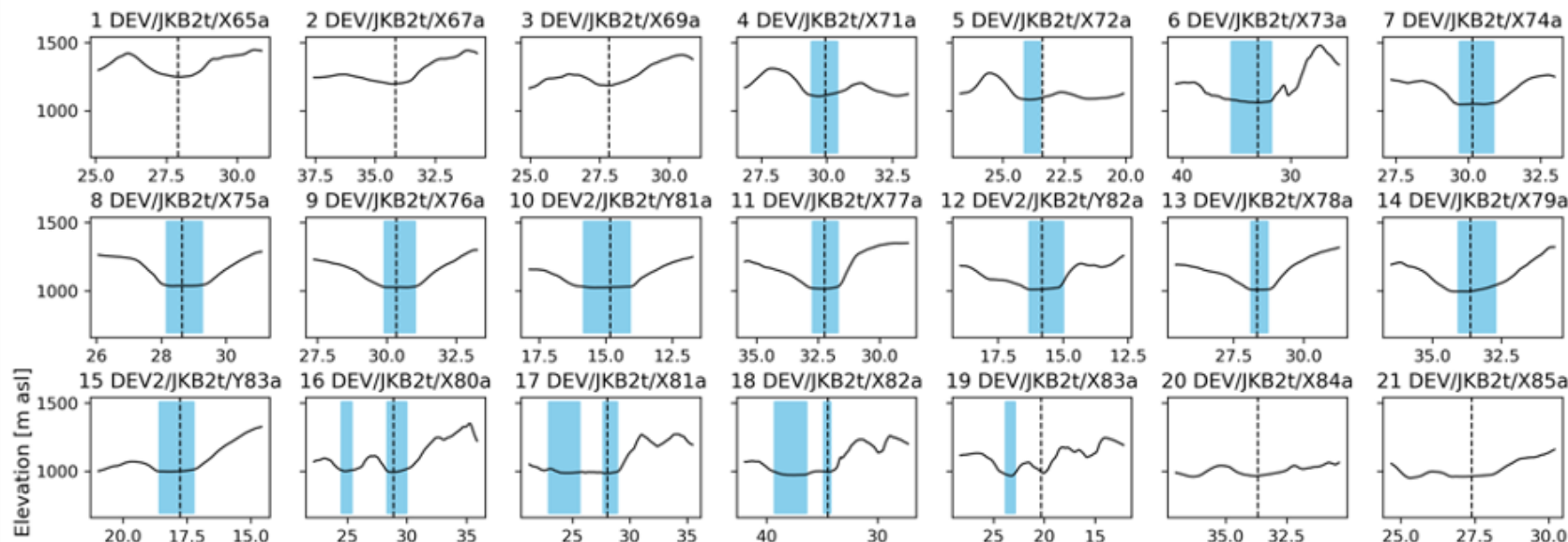

$\begin{array}{lll}27.5 & 30.0 & 32.5 \\ 16 & \text { DEV/JKB2t/X80a }\end{array}$
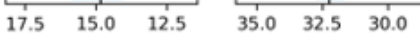

$\begin{array}{lll}17.5 & 15.0 & 12.5\end{array}$

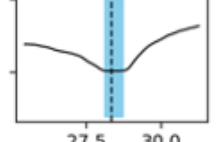

$17 \mathrm{DEV} / \mathrm{KB} 2 \mathrm{~K} / \mathrm{X} 81$

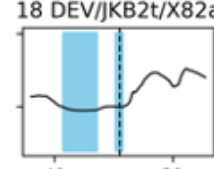

$19 \mathrm{DEV} / \mathrm{KB} 2 \mathrm{t} / \mathrm{X} 83$

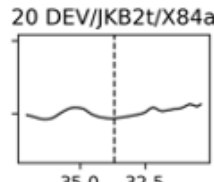

$40 \quad 30$

X91a
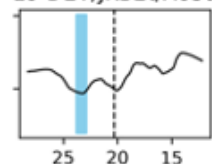

$35.0 \quad 32.5$

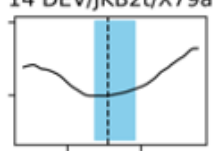

$35^{\prime} .0 \quad 32.5$
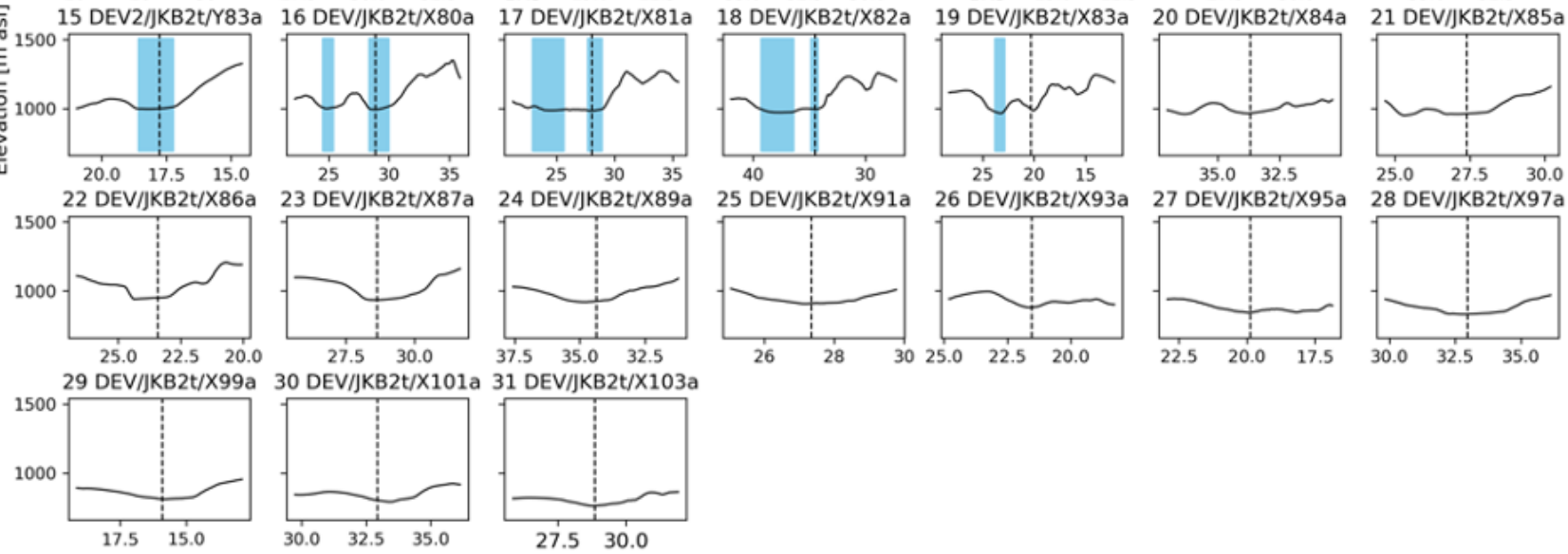

Distance [km]

Figure S8. Bedrock elevation along radar profiles over bedrock trough T2 and its canyon extension. Areas over the subglacial lakes are shaded with blue. Vertical dashed lines represent the approximate trough center. Profiles named DEV2 $(10,12,15)$ are the profiles flown at a $45^{\circ}$ angle over $\mathrm{T} 2$. 


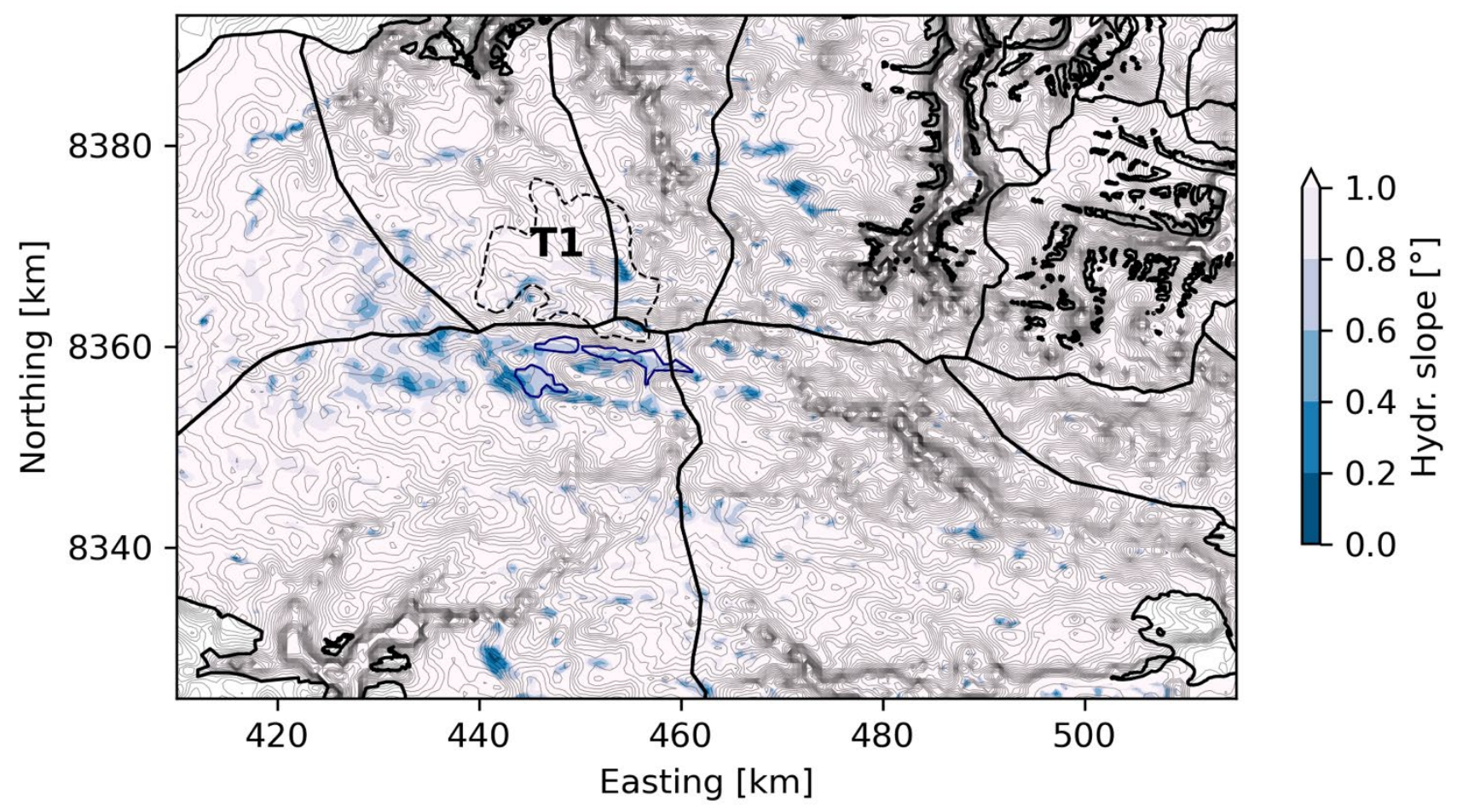

Figure S9. Map showing areas with hydraulic slopes $<1^{\circ}$. Thin black lines represent the bedrock topography ( $25 \mathrm{~m}$ interval) whereas thick black lines mark the location of the ice divides. Outlines of the subglacial lakes A-C are marked in blue, and the brine network surrounding the T1 area is marked with the black dashed line. 

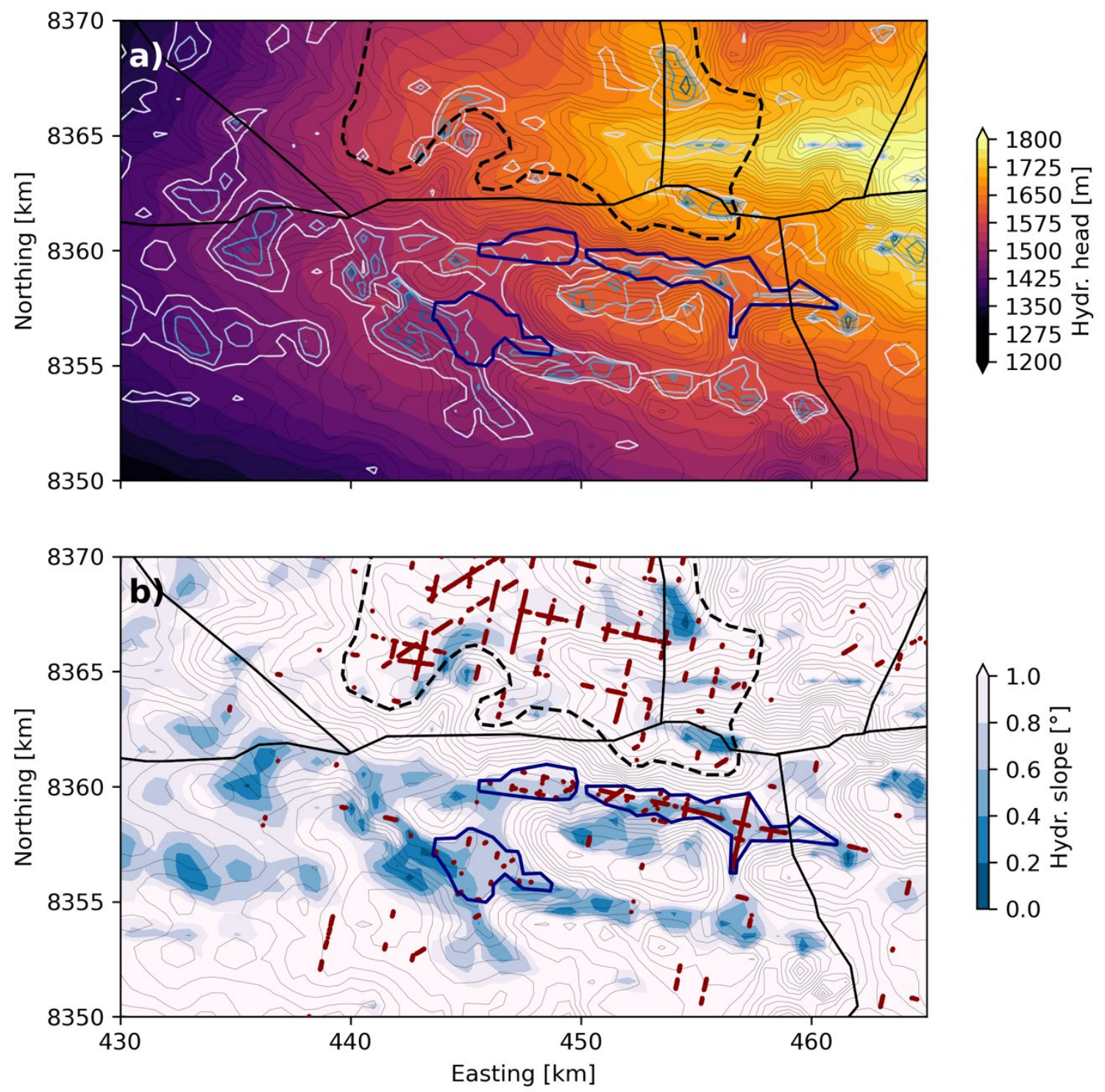

Figure 10. Hydraulic head (a) and slope (b) in the area of the subglacial lakes A-C (blue outlines). Contours in a) correspond to the hydraulic slope marked on b). Red dots represent reflectivity anomalies larger than $12 \mathrm{~dB}$, and black dotted line marks the outline of the interpreted subglacial brine network. 


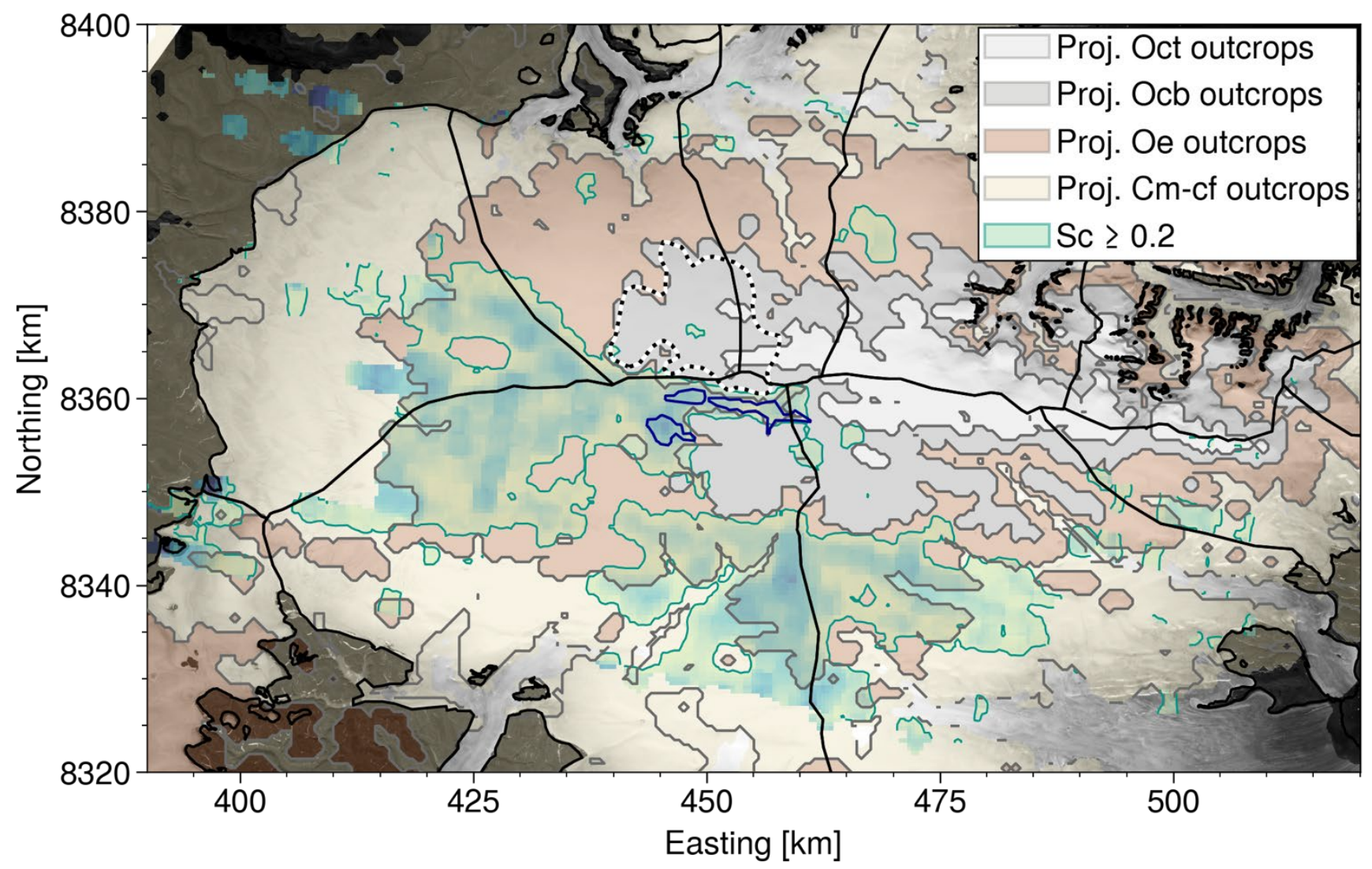

Figure S11. Landsat image overlain with the projected outcrops of different geological units, areas of high specularity content Sc and the locations of the subglacial lakes (blue) and brine network (black-white dotted line). The geological units were projected using the geology model from (Rutishauser et al., 2018) and the updated bed topography DEM from this study. Details on the geological units can be found in (Harrison et al., 2016), (Mayr, 1980) and (Thorsteinsson and Mayr, 1987). 


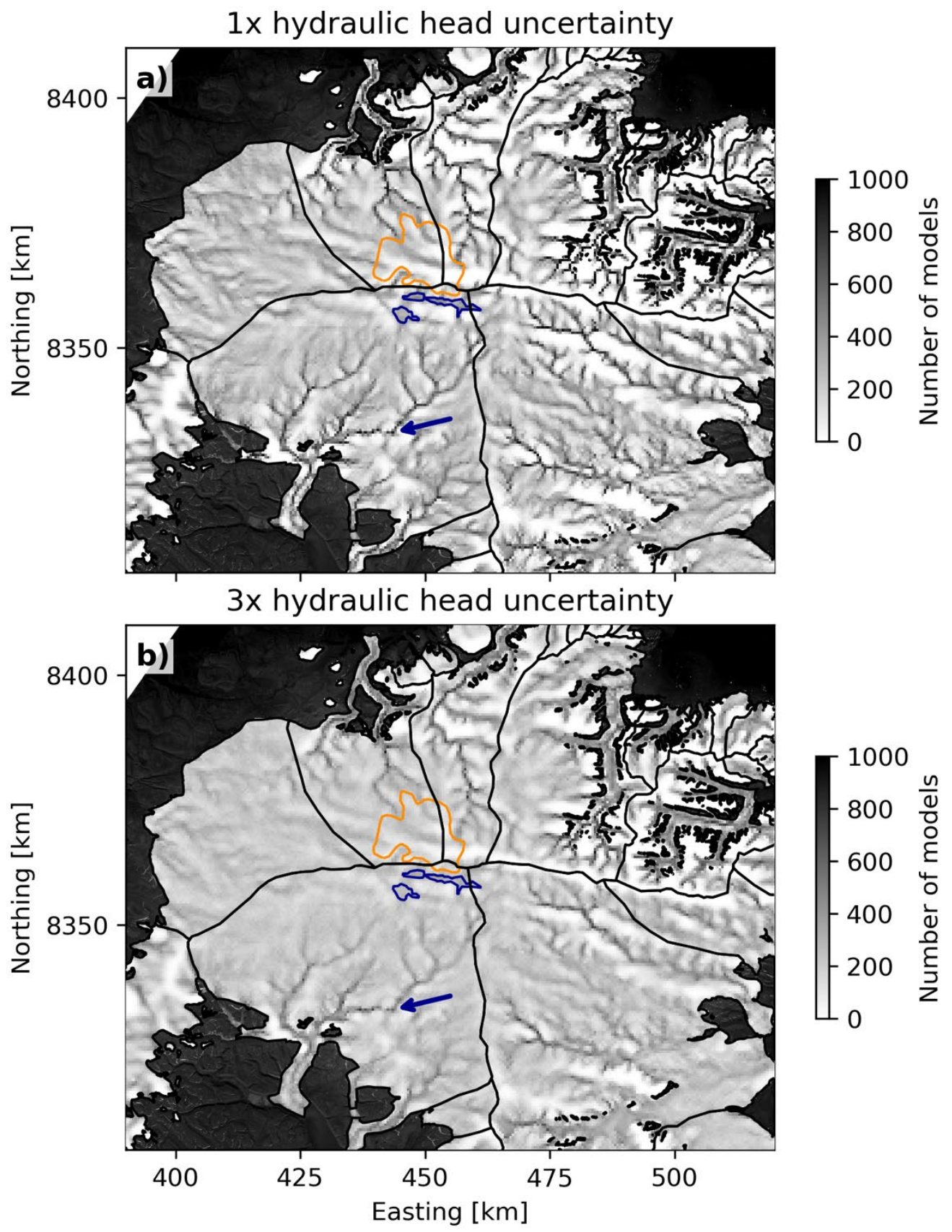

Figure S12. Modeled potential subglacial hydrological pathways beneath DIC, using one (a) and three (b) times the uncertainty of the hydraulic head as randomly distributed errors. Outlines of the subglacial lakes and brine network are marked in blue and orange, respectively. Arrow marks the location where there is remaining uncertainty if water flow from the subglacial lakes would flow into North Croker Bay Glacier or South Croker Bay Glacier. 


\section{References}

Harrison, J. C., Lynds, T., Ford, A., and Rainbird, R. H.: Geology, simplified tectonic assemblage map of the Canadian Arctic Islands, Northwest Territories - Nunavut, Map 80, https://doi.org/10.4095/297416, 2016.

Mayr, U.: Stratigraphy and correlation of lower Paleozoic formations, subsurface of Bathurst Island and adjacent smaller islands, Canadian Arctic Archipelago, 306, 1980.

Porter, C., Morin, P., Howat, I., Noh, M.-J., Bates, B., Peterman, K., Keesey, S., Schlenk, M., Gardiner, J., Tomko, K., Willis, M., Kelleher, C., Cloutier, M., Husby, E., Foga, S., Nakamura, H., Platson, M., Wethington Jr., M., Williamson, C., Bauer, G., Enos, J., Arnold, G., Kramer, W., Becker, P., Doshi, A., D’Souza, C., Cummens, P., Laurier, F., and Bojesen, M.: ArcticDEM, https://doi.org/10.7910/DVN/OHHUKH, 2018.

Rutishauser, A., Blankenship, D. D., Sharp, M., Skidmore, M. L., Greenbaum, J. S., Grima, C., Schroeder, D. M., Dowdeswell, J. A., and Young, D. A.: Discovery of a hypersaline subglacial lake complex beneath Devon Ice Cap, Canadian Arctic, 4, eaar4353, https://doi.org/10.1126/sciadv.aar4353, 2018.

Schroeder, D. M., Blankenship, D. D., Raney, R. K., and Grima, C.: Estimating Subglacial Water Geometry Using Radar Bed Echo Specularity: Application to Thwaites Glacier, West Antarctica, 12, 443-447, https://doi.org/10.1109/LGRS.2014.2337878, 2015.

Thorsteinsson, R. and Mayr, U.: The sedimentary rocks of Devon island, canadian arctic archipelago, 182 pp., https://doi.org/10.4095/122451, 1987. 